\title{
Recent losses of perennial cover in a Great Lakes agricultural region
}

\author{
Robert C. Corry \\ Centre for Land \& Water Stewardship, Landscape Architecture, University of Guelph, Canada N1G 2 W1 \\ Email: rcorry@uoguelph.ca \\ Phone: (519) 824-4120x58034
}

Acknowledgements

This research was supported in part by a grant from the Landscape Architecture Canada Foundation.

This is a submitted version of a manuscript that appears in The Canadian Geographer. The full citation information is:

Corry, Robert C. 2017. Recent losses of perennial cover in a Great Lakes agricultural region. The Canadian Geographer, xx(xx): 1-10. DOI: 10.1111/cag.12431 


\title{
Recent losses of perennial cover in a Great Lakes agricultural region
}

\author{
Robert C. Corry \\ Centre for Land \& Water Stewardship, Landscape Architecture, University of Guelph, Canada N1G 2W1 \\ Email: rcorry@uoguelph.ca
}

Phone: (519) 824-4120x58034

A R T I C L E I N F O

Article history:

Received 7 Feb 2017

Revised 13 Jun 2017

Accepted 26 Jun 2017

Available online 14 Dec 2017

DOI: $10.1111 /$ cag. 12431

Keywords:

Landscape pattern

Farming

Landscape change

Conversion

Land stewardship

\begin{abstract}
A B S T R A C T
Landscape composition is consequential to ecological functions, and in agricultural regions a simple descriptor of composition is whether the growing habit of vegetation is annual or perennial. Annual vegetation includes most of the crop species grown in central North America (e.g., corn, soybeans, cereal grains, canola), and perennial vegetation includes hay and forage crops (e.g., alfalfa) and most non-crop land covers (e.g., woodlands, grasslands, wetlands). Recent data show that in farmlands perennial cover is converting to annual cover. Using new remotelysensed annual crop layer spatial data for an intensively-farmed region $\left(1,700 \mathrm{~km}^{2}\right)$ of the Lake Huron watershed in Southern Ontario, Canada, this article describes changes in farmland composition and which transitions are occurring, with suggestions for why the changes are occurring. Perennial cover has rapidly been converted to annual cover in the past five years, with working-lands perennial cover types identified as the most-vulnerable to conversion. Other land cover types are relatively static. Implications for agricultural land conservation and stewardship require attention to this rapid change for conservation of soil, water, and biodiversity in the Great Lakes basin.
\end{abstract}

\section{Introduction}

Changes in landscape pattern are fundamental to the ecological and cultural services that landscapes provide. The structure, function, and change of land cover types across broad spatial areas is useful for estimating the flows of materials, energy, and species across landscapes (Risser, Karr et al. 1984, Forman 1995). This article focuses on observed structure and change in an agricultural landscape - that is, on the composition of farmlands with a focus on vegetation type and how this has changed in a recent period.

The amount of perennial and annual vegetative cover in farmlands is consequential to soil, water, wildlife, and social outcomes (Asbjornsen, Hernandez-Santana et al. 2013) and perennial cover has been elaborated as a principal way to achieve important societal benefits from agricultural landscapes (Schulte, Liebman et al. 2006, Liebman and Schulte 2015). Similarly, heterogeneity in farmlands is sought to improve ecological services (Lin 2011). Heterogeneity includes both working perennial cover (as part of the farm economic enterprise) and non-farmed perennial cover that primarily provides ecosystem services (Schulte, Liebman et al. 2006). Patterns of field layout and field boundaries have a significant effect on heterogeneity and biodiversity across the farm landscape (Fahrig, Girard et al. 2015). The pattern of farmlands - including non-cropped and actively farmed portions - merits monitoring to understand fundamental relationships between landscape composition and ecosystem services.

Environmental programs for farms have historically relied on perennial cover for the 
most substantial benefits for soil, water, and wildlife conservation (Steiner 1990)(XXX, 2013a masked for blind review) and after decades of farm conservation programming a principal finding is the critical role of perennial cover in achieving desirable outcomes (Eilers, MacKay et al. 2010, Cox, Hug et al. 2011)(XXX, 2013b masked for blind review). De-intensifying agricultural landscapes has been described as needed to reverse degradation of farmlands (Norton 2016), yet farming continues to become more intensive (Ramankutty, Evan et al. 2008).

Farm landscapes change over short and long time periods. Crop rotations change the landscape annually (occasionally seasonally), while changes in farm enterprise or crop selection typically happen over longer time frames. Agricultural landscape changes in Canada and Ontario have been documented at broad spatial and temporal scales, including environmental implications such as nitrogen loss, soil erosion, and biodiversity loss (Eilers, MacKay et al. 2010). A scan of agriculture in eastern Canada (Pearson, Bucknell et al. 2008) showed that from 1960 to 2000 farm composition became increasingly dominated by annual crops with less perennial pasture and forage cover types - even where cropping potential is marginal. At the same time, changes in grazing livestock (that is, domestic animals that eat perennial forages) are well-documented with declines in cattle, sheep, goats, and horses across Canada and the USA (Sulc and Tracy 2007)(XXX, 2013a masked for blind review).

Ontario agricultural census data enumerate declines in perennial cover and grazing livestock: for example, the area of the province's pastureland decreased from 1.01 million ha in 1996 to 0.54 million ha in 2011 , a $34.8 \%$ decrease in 15 years. In the same period the number of cattle and calves decreased $24.0 \%$, from 2.29 million to 1.74 million head (Ontario Ministry of Agriculture Food and Rural Affairs 2016). In the Great Lakes watersheds of southern Ontario annual crops have increased in area - particularly for corn and soybeans with smaller increases in (winter) wheat area. Perennial hay and pasture area dropped in the period just after World War II to the early 2000s, sometimes precipitously (XXX, 2013a masked for blind review).

While differences in annual and perennial cover are documented, these are not the only land cover types in agricultural regions. Built land covers such as farmsteads, settlements, and roads, along with surface waters (lakes, ponds, rivers) are part of the rural landscape. Farmland converted to non-agricultural land uses in Ontario between 2006 and 2011 occurred at a rate of approximately $135 \mathrm{ha} /$ day [emphasis mine], a loss rate of $4.8 \%$ over the five-year period (Statistics Canada 2012). Changes in perennial or annual cover are not simply circular exchanges between annual and perennial vegetation, but among all the land cover types in the rural landscape.

Notably, only $5 \%$ of Canada is high-quality agricultural land; of Canada's best agricultural land (Canada Land Inventory, Class I), 51\% is in Ontario and it is estimated that more than onefifth of this agricultural land is occupied by nonagricultural uses (Watkins, Hilts et al. 2003). Agricultural census data for 2011 show that the ratio of croplands (all cultivated land) to woodlands and wetlands on Ontario farms is about 5.6-to-1 (Statistics Canada 2012). For a county in the middle of intensively-farmed south-western Ontario (Huron County), the ratio is about 9.5-to-1 (Statistics Canada 2012). While this does not account for woodlands and wetlands that are not part of farms (i.e., not part of agricultural census data), southern Ontario is substantially privately-owned. In summary, the best farmland in Canada is nationally-rare, provincially-concentrated, and rapidly converted to other uses. Farms are about 5-9 times more likely to be cropped than have remnant perennial land covers.

In order to understand how much change has occurred in the recent past, and to know the dynamics of different land cover types, this article reports on measurements of spatial change in rural southern Ontario. Using the federal government agency Agriculture and Agri-Food Canada (AAFC) annual crop layer data (an interpretation of yearly geo-spatial, 
remotely-sensed land covers), this article documents changes in annual, perennial and other rural land cover types from 2011 to 2015 and show trajectories of change among different land cover types. The analysis provides documentation of rural landscape change that provides a baseline using newly-available agricultural landscape data.

\section{Methods}

AAFC annual crop layer data exist beginning in 2011 with annual updates. The annual crop layer identifies all land cover types in agricultural regions, with focused differentiation of farm cover types. These data are derived Canada-wide every growing season and interpreted from satellite imagery at a typical spatial resolution of $30 \mathrm{~m}$. Landsat 5 Thematic Mapper (TM), Advanced Wide-Field Sensor (AWiFS), and Disaster Modeling Constellation (DMC) satellite imagery form the basis for the land cover interpretations (Boryan and Craig 2006). AAFC requires a minimum Canada-wide accuracy for the data to average at or above $85 \%$ and documents the accuracy for crop class interpretations for Ontario for 2011-15 to be $82 \%, 76 \%, 87 \%, 87.9 \%$, and $89.6 \%$ respectively (Agriculture and Agri-food Canada no date). The land cover data for 2014 and 2015 indicate that secondary roads are better represented as a built land cover type instead of vegetation (their classification in 2011-13) (Figure 1).

Insert Figure 1 approximately here

For an area of southern Ontario, the AAFC annual crop layer data were bounded in a rectangular study area (approximately 30 by 59 $\mathrm{km}$; see Figure 2). The study area was chosen as midway between the southern limit of Ontario (near the Lake Erie shoreline) and the southern shore of Georgian Bay on Lake Huron, constituting part of the most intensively-farmed portion of the province and a high concentration of Class I agricultural land (highest agricultural capacity in Canada) (XXX 2013, masked for blind review). The western limit of the study area was the Lake Huron shoreline, and the east extent approaches parts of the watershed boundary for the Lake Huron catchment area. The study area is at a transition where to the south the landscape is dominated by annual cropping (Middlesex, Chatham, Kent, Essex Counties), and to the north the landscape is dominated by mixed farming and grazing livestock (Grey and Bruce Counties). In the study area row crops tend to dominate in the southern portion while hay and forage appear more common in the northern portion. The study area, including parts of the Lake Huron shoreline, is about $1,774 \mathrm{~km}^{2}(177,400 \mathrm{ha})$, a regional scale (Forman 1995).

Insert Figure 2 approximately here

ArcGIS was used to define the study area boundary and re-classify AAFC annual crop layer data. The original AAFC land cover classes were collapsed into five classes: water, built, annual crops, short-term perennial cover (typically herbaceous and in this region often working lands), and long-term perennial cover (typically woody and in this region commonly non-farmed lands; Table 1). All existing land cover types fit the collapse; for this part of the AAFC data there were no undifferentiated pixels or unidentified cover types. Areas of different land cover types were compared in terms of annual change and overall change. In addition, the land cover types that changed between 2011 and 2015 were documented to understand the regional areal dynamics and direction of conversion between the two ends of the period. Results show the dynamism of land cover types at the beginning of the AAFC annual crops layer data collection.

Insert Table 1 approximately here

\section{Results}

In 2011 the study area was $29.7 \%$ perennial land cover types, with that approximately evenly-split between short-term (15.4\%) and long-term (14.3\%) cover types. Perennial cover ranged from a high of $31.2 \%$ of the study area in 2012 to a low of $28.4 \%$ in 2015 (a difference of 4,969 ha). Short-term perennial cover diminished relative to long-term cover over time, and by 2015 long-term perennial cover accounted for $57.6 \%$ of perennial land cover types (Table 2). 
Annual crop cover varied from a low of $64.1 \%$ of study area (2014) to $66.2 \%$ (2013). There was not a clear trend in annual cover over five years and its proportional and actual changes were more modest compared to other vegetation types (varying by 3,580 ha in actual change; Table 2).

The yearly trend in cover types among annuals and perennials is more variable for those that are commonly pasture/hay and woodlands (Table 3 ). While annual crops varied not more than $+/-3 \%$ from year-to-year (range of 3,580 ha), perennials had changes from $-8 \%$ to $+11 \%$ on an annual basis (range of 5,421 and 5,856 ha), and the range was highest for short-term perennial types. Over the five years of data the range of land cover change was $22 \%$ (from -8 to $+14 \%$ for long-term perennials; from -22 to $0 \%$ for shortterm perennials). Greatest changes in perennial proportions came in 2012 and 2014 for longterm and short-term cover, respectively (Figure $3)$.

Insert Table 2 approximately here

Insert Table 3 approximately here

\section{Land cover Type Dynamics}

About $52.0 \%$ of the area of the land covers did not change in the five-year study period. The area of water was $87.0 \%$ unchanged. When it did change, water was reclassified as perennial vegetation in $9.8 \%$ of its original area, annual vegetation in $0.6 \%$ of its area, and built land cover in $2.7 \%$ of its area. The area of built land cover types did not change for $63.6 \%$ of occurrences. Built land covers changed to annual vegetation cover in $17.9 \%$ of their area, to shortterm perennial vegetation in $11.7 \%$ of their area, and to long-term perennial vegetation cover in $5.4 \%$ of their area.

Annual vegetation land cover area was unchanged about one-third of the time (34.5\% of occurrences). When annual land cover changed, $39.0 \%$ of that change was to short-term perennial vegetation cover and $15.7 \%$ was to long-term perennial vegetation. In the period of the data $10.7 \%$ of annual vegetation became built land cover (this appears to partially be due to better classification of secondary - gravel road surfaces in 2014 and 2015 - see Figure 1).

Short-term perennial land cover area remained the same $32.9 \%$ of the time. Shortterm perennial land cover converted to annual vegetation in $51.1 \%$ of its area, and to long-term perennial vegetation for $8.7 \%$ of its area.

Long-term perennial vegetation area did not change for $85.0 \%$ of occurrences across the time period. $9.7 \%$ of changes in area were conversions to annual vegetation and $3.2 \%$ of changes in area were to short-term perennial vegetation.

$$
\text { Insert Figure } 3 \text { approximately here }
$$

\section{Discussion}

The overall proportions of perennial cover in the study area align with expectations for one Canada's most-capable agricultural regions, with proportions of perennial vegetation below $32 \%$ over all study years. Previous analysis of small, intensively-cropped landscapes have found proportions of perennial cover as low as $4-10 \%$ (Brown and Schulte 2011), but across larger regions and when including non-farmed areas this value increases. For Huron County an index of cropping intensity (ratio of row-cropped land to total farm area) was 0.66 in 2006 (XXX, 2013a masked for blind review), comparable to a proportion of $32 \%$ perennial cover.

Of the perennial vegetation land cover, most $(57 \%)$ is long-term cover (predominantly woody vegetation in this region), and long-term perennial cover expanded in area over time at $14 \%$ more in 2015 than in 2011 , at least some of which is due to improved classification (accuracy rates increased from $82 \%$ to $89.6 \%$ in the period). This long-term perennial vegetation is more likely to be stable and durable because of the challenges of converting woody or wetland vegetation to cropland (see Table 1), though in parts of the Western Corn Belt (USA) recent conversion of marginal lands has been rapid (Wright and Wimberly 2013). Long-term perennial cover is that which commonly provides ecosystem services to agriculture, including wind attenuation, pest suppression, 
pollinator provisions, water infiltration and storage, and carbon storage (Steiner 1990, Schulte, Liebman et al. 2006, Landis 2016).

Short-term perennial vegetative cover decreased by 5,856 ha over time, dropping $22 \%$ in area over five years of mapping. This decrease in short-term perennial vegetation is consistent with periodic census data showing decreases in the area of pasture and forage across Huron County and Ontario. The area of annual cover was not so highly variable in proportion and did not appear to show a trend in this five-year period. Annual cover was consistently the dominant component of the landscape - it was always more than $64 \%$ of the study area. Annual cover did vary up to 3,580 ha, compared to short-term perennial cover's range that was greater than 2,200 ha more variable, meaning that the changes were not simply circular rotations between these two cover types.

The ratio of annual to perennial vegetation in the study is $2.3: 1$. This is lower than Ontario and Huron County averages because this study considers the region's entire landscape, not just farmlands (as with agriculture census data cited in Introduction) or privately-owned land. Likewise, "cropped" land in the agricultural census includes hayfields which are classified as "perennial" here - so the ratio of annual to perennial is not absolutely equivalent to the ratio of cropland to woodland/wetland. In a proposed 50-year Farm Bill for the USA, a 1:4 ratio of annual to perennial vegetation is proposed to achieve a more-sustainable agriculture (Jackson 2010). There is a wide chasm between the existing and an ideal ratio of annual to perennial vegetation within this agricultural region.

The changes among land cover types overall were less than those that did not change. For the five-year period, $52 \%$ of land cover area did not change types. However, this was not consistent across all land cover types. Built, water, and long-term perennial land cover types had the most stable areas, where between 63 and $87 \%$ of those types remained the same. For annual vegetation types, their greatest conversion was to short-term perennial vegetation (more than the area that did not change at all), and for shortterm perennial vegetation the greatest conversion was to annual cover (exceeding the area that did not change). These changes point to some relative stasis among built, surface waters, and woody perennial covers, yet an alternating rotation between some of the short-term perennial covers (i.e., those that are herbaceous) and annual crops within this observation period.

The transition between short-term perennial and annual covers is consistent with rotations of perennial forages and annual row crops something that might be sequenced in a six-year cycle. A six-year rotation might be corn/soybeans/wheat/alfalfa hay for three years, before returning to corn (Ontario Ministry of Agriculture Food and Rural Affairs 2009). While the area of annual cover remained relatively static across the study years (declining 1,320 ha from 2011 to 2015), short-term perennial cover diminished the most (declining 5,856 ha in the same period). Some of this change can be attributed to better classification of land cover types (e.g., roads) for improved accuracy.

Another implication is that while the rotation between annual and short-term perennial cover is among the most-common short-term sequence in this agricultural region, a trend might be developing to less perennial cover in this rotation over time. That is, if a common agronomic rotation is a six-year sequence (corn/soybeans/wheat/hay/hay/hay), it may have shifted to a more annual-based sequence (e.g., where rotations include less short-term perennial vegetation in the cycle or none at all). Shortened rotation sequences or moving away from perennials in rotation is associated with a decline in forage-fed livestock and could result in less short-term perennial vegetation. Having only four transition sequences (five years of data) to compare in a landscape where rotations might commonly run between three and six years in duration limits inferences about generalities across rotation cycles.

In this 2011-15 period, crop prices for corn and soybeans were higher than a longer-term average and this has been attributed to American 
and Canadian ethanol policies. The Renewable Fuel Standard (USA) and Canadian Renewable Fuel Regulations incentivize corn-starch ethanol blending into gasoline (Dessureault 2014, Condon, Klemick et al. 2015, Lark, Salmon et al. 2015), and trade agreements means that commodity corn moves across the nearby Canada/USA border (XXX, 2013a masked for blind review).

Ontario is the largest producer of bio-ethanol in Canada, producing 58\% of the nation's ethanol in seven plants. Plants in southern Ontario use corn as a primary feedstock in four locations (Tiverton, Aylmer, Chatham, and Sarnia) that are all within a two-hour truckingdistance of this study area. These ethanol plants have a combined capacity of 790 million $\mathrm{L}$ of bio-ethanol per year (Dessureault 2014). At a conversion rate of $10.71 \mathrm{~L}$ of ethanol per bushel of corn (Kwiatkowski, McAloon et al. 2006), this capacity is equivalent to a requirement of approximately 73.76 million bu of corn (note: imperial units for yield, bushel weight, and farming area are used here because of cultural conventions). Huron County's average grain corn yield for 2011-15 is $165.0 \mathrm{bu} / \mathrm{ac}$ (10.36 t/ha) (Ontario Ministry of Agriculture Food and Rural Affairs 2016). This volume of ethanol (790 million L), coming from grain corn, requires 447,048 ac (180,918 ha) of corn using Huron County's average yield.

The corn used in these ethanol plants comes from all over southern Ontario, yet it is salient that a relatively new use for corn demands over 180,000 ha' production to satisfy it, about 3,500 ha more than the area of this study. Huron County's average corn production area was 71,308 ha in the study period, some of which would be for ensiling directly. The ethanol plants are capable of using more than $2 \frac{1}{2}$ times the area of all the corn grown in Huron County. A commodity growers' organization, Grain Farmers of Ontario, commissioned a 2016 "market utilization overview" that reports $37 \%$ of Ontario corn is used for ethanol and industrial uses.

A reduction in perennial cover is consequential for agricultural land stewardship.
While the proportions of perennials are modest overall, the rapid decrease of short-term perennial cover (an average of more than 1,100 $\mathrm{ha} / \mathrm{yr}$ ) is concerning. Perennial cover has been identified as fundamental to achieving a more sustainable agriculture (Schulte, Liebman et al. 2006, Asbjornsen, Hernandez-Santana et al. 2013) and historically is the leading way of protecting soil and water (Steiner 1990, Jackson 2010) and contributing to landscape heterogeneity (Lin 2011, Landis 2016). Decreases in grazing livestock and perennial cover are documented across central North American landscapes, while increases of annual row cropping and associated concerns with soil erosion, nutrient loss and pollution, and diminished biodiversity have led to new environmental concerns (Nassauer, Santelmann et al. 2007, Eilers, MacKay et al. 2010, Cox and Hug 2012, Davis, Hill et al. 2012). The changes in this Lake Huron agricultural region are consistent with changes across eastern Canada, from Ontario to the Maritimes (Pearson, Bucknell et al. 2008).

Two environmental consequences of agriculture are acute in southern Ontario: loss of grassland habitat with implications for grassland-limited species, and increases in bluegreen algae and dissolved reactive phosphorus in the lower Great Lakes, especially the western basin of Lake Erie. Loss of hay and forage cover is linked to declines of species limited to grasslands, particularly birds such as the eastern meadowlark (Sturnella magna) and bobolinks (Dolichonyx oryzivorus), and mammals like the American badger (Taxidea taxus). These species are threatened in Ontario and new farm conservation programs have been launched to target habitat and management to support these fauna (e.g., species-at-risk farm incentive program [SARFIP]; grassland habitat initiative [GHI]). Similarly, there is an increase in dissolved reactive phosphorus in the lower Great Lakes and blue-green algae outbreaks that are partially consequences of agricultural land uses and management, including annual row cropping (Michalak, Anderson et al. 2013). Agricultural watersheds in Great Lakes basins in the USA suffer from intensive annual row crop production (Hawley, Johengen et al. 2006). New 
farm programs for southern Ontario are attempting to address these consequences with better nutrient and soil management (e.g., Great Lakes agricultural stewardship initiative [GLASI]), even as perennial cover declines.

Land stewardship policies to combat concerns like hypoxia or blue-green algae outbreaks in the lower Great Lakes might be more effective if they monitor landscape patterns for changes in land cover types. Because of the conservation potential of perennial vegetative cover, either as a working part of the farm or as a non-farmed ecosystem service provider, a fundamental measure of agricultural landscape patterns is the trajectory of their composition over time. Other changes to monitor include landscape pattern attributes like field size (Fahrig, Girard et al. 2015), mix of land cover types (Landis 2016), and disturbance regimes (Donald 2004). For this representative part of southern Ontario the decline in short-term perennial vegetation (working lands) is likely to have a lasting effect on declines in land and water stewardship outcomes.

\section{Conclusion}

Changes in land cover types within farms and across agricultural landscapes has critical consequences for soil erosion, habitat characteristics, and the look of farmlands, and perennial land cover types have a thorough record of environmental benefits. Longer-term assessments of the spatial changes among cover types is needed to know what transitions are occurring and how they intersect with rotation sequence timing (that is, with the annual changes among crops and forages), including - for example - assessments that are generalized across a few crop rotation cycles. Increasingly fine-resolution data - like those of the National Agriculture Imagery Program (NAIP) (United States Department of Agriculture Farm Service Agency No date, web resource) - that identify small (one metre in dimension) features like field boundary vegetation, stream buffers, roadside verges, and individual trees will improve the understanding of agricultural landscape composition, especially as monitored over long time periods (Poschlod and Braun-
Reichert 2016)(XXX, 2002, masked for blind review). Farm landscapes that are examined across time and space will capture changes in land cover and management - including rotation sequences - that could lead to improved regulations, incentives, or programs to address environmental consequences of agriculture.

Reliable spatial analysis can help to corroborate agricultural census responses that might not accurately capture landscape changes (Statistics Canada no date, web report) leading to better data on landscape structure and management. Annual changes in farming (including crop rotations) and longer-term trends have not been readily understood from agricultural census data or small-extent studies that can be difficult to generalize. Some farm management techniques remain difficult to capture, such as cover crops or double-cropping where two crops are grown in a single growing season. Both census reporting and remotesensing of land covers are challenged in how they can interpret cover- and double-cropping techniques. Broad-extent spatial data like the annual crop layer can improve understanding of landscape pattern changes that implicate environmental, societal, and economic policies. For land and water stewardship outcomes that are important to society, reliable and appropriately scaled landscape data are needed to match policies to farmland changes.

\section{References}

Agriculture and Agri-food Canada (no date). ISO 19131 AAFC Annual Crop Inventory - Data Product Specification, Revision A. Ottawa, Agriculture and Agri-food Canada: 21.

Asbjornsen, H., V. Hernandez-Santana, M. Liebman, J. Bayala, J. Chen, M. Helmers, C. K. Ong and L. A. Schulte (2013). "Targeting perennial vegetation in agricultural landscapes for enhancing ecosystem services." Renewable Agriculture and Food Systems 29(02): 101-125

Boryan, C. and M. Craig (2006). Multiresolution Landsat TM and AWIFS Sensor Assessment for crop area estimation in Nebraska. Global Priorities in Land Remote Sensing, Sioux Falls, South Dakota, USDA NASS.

Brown, P. W. and L. A. Schulte (2011). "Agricultural landscape change (1937-2002) in three townships in Iowa, USA." Landscape \& Urban Planning 100(3): 202-212. 
Condon, N., H. Klemick and A. Wolverton (2015). "Impacts of ethanol policy on corn prices: A review and meta-analysis of recent evidence." Food Policy 51: 63-73.

Cox, C. and A. Hug (2012). Murky Waters: Farm Pollution Stalls Cleanup of Iowa Streams. Washington, DC, Environmental Working Group: 52.

Cox, C., A. Hug and N. Bruzelius (2011). Losing Ground. Washington, DC, Environmental Working Group: 37.

Davis, A. S., J. D. Hill, C. A. Chase, A. M. Johanns and M. Liebman (2012). "Increasing cropping system diversity balances productivity, profitability and environmental health." PLoS One 7(10): e47149.

Dessureault, D. (2014). Canada Biofuels Annual. Washington, DC, United States Department of Agriculture, Foreign Agricultural Service: 30.

Donald, P. F. (2004). "Biodiversity impacts of some agricultural commodity production systems." Conservation Biology 18(1): 17-37.

Eilers, W., R. MacKay, L. Graham and A. Lefebvre, Eds. (2010). Environmental Sustainability of Canadian Agriculture, Report \#3. Agri-Environmental Indicator Report Series. Ottawa, Ontario, Agriculture and AgriFood Canada.

Fahrig, L., J. Girard, D. Duro, J. Pasher, A. Smith, S. Javorek, D. King, K. Lindsay, S. Mitchell and L. Tischendorf (2015). "Farmlands with smaller crop fields have higher within-field biodiversity." Agriculture Ecosystems \& Environment 200: 219-234.

Forman, R. T. T. (1995). Land Mosaics. Cambridge, Massachusetts, Cambridge University Press.

Hawley, N., T. H. Johengen, Y. R. Rao, S. A. Ruberg, D. Beletsky, S. A. Ludsin, B. J. Eadie, D. J. Schwab, T. E. Croley and S. B. Brandt (2006). "Lake Erie hypoxia prompts Canada-U.S. study." EOS, Transactions, American Geophysical Union 87(32): 313-324.

Jackson, W. (2010). Consulting the Genius of the Place. Berkeley, California, Counterpoint.

Kwiatkowski, J. R., A. J. McAloon, F. Taylor and D. B. Johnston (2006). "Modeling the process and costs of fuel ethanol production by the corn dry-grind process." Industrial Crops and Products 23(3): 288-296.

Landis, D. A. (2016). "Designing agricultural landscapes for biodiversity-based ecosystem services." Basic and Applied Ecology In Press.

Lark, T. J., J. M. Salmon and H. K. Gibbs (2015). "Cropland expansion outpaces agricultural and biofuel policies in the United States." Environmental Research Letters 10(4): 11.

Liebman, M. and L. A. Schulte (2015). "Enhancing agroecosystem performance and resilience through increased diversification of landscapes and cropping systems." Elementa: Science of the Anthropocene 3: 000041 .

Lin, B. B. (2011). "Resilience in agriculture through crop diversification: Adaptive management for environmental change." Bioscience 61(3): 183-193.

Michalak, A. M., E. J. Anderson, D. Beletsky, S. Boland, N. S. Bosch, T. B. Bridgeman, J. D. Chaffin, K. Cho,
R. Confesor, I. Daloğlu, J. V. DePinto, M. A. Evans, G. L. Fahnenstiel, L. He, J. C. Ho, L. Jenkins, T. H. Johengen, K. C. Kuo, E. LaPorte, X. Liu, M. R. McWilliams, M. R. Moore, D. J. Posselt, R. P. Richards, D. Scavia, A. L. Steiner, E. Verhamme, D. M. Wright and M. A. Zagorski (2013). "Recordsetting algal bloom in Lake Erie caused by agricultural and meteorological trends consistent with expected future conditions." Proceedings of the National Academy of Sciences 110(16): 6448-6452.

Nassauer, J. I., M. V. Santelmann and D. Scavia, Eds. (2007). From the Corn Belt to the Gulf: Societal and Environmental Implications of Alternative Agricultural Futures. Washington, DC, Resources for the Future Press.

Norton, L. R. (2016). "Is it time for a socio-ecological revolution in agriculture?" Agriculture, Ecosystems \& Environment 235: 13-16.

Ontario Ministry of Agriculture Food and Rural Affairs (2009). Agronomy guide for field crops. Toronto, Ontario, Ministry of Agriculture, Food and Rural Affairs.

Ontario Ministry of Agriculture Food and Rural Affairs. (2016, 31 October 2016). "Field Crops: Area and Production Estimates." Retrieved 3 November 2016, 2016, from

http://www.omafra.gov.on.ca/english/stats/crops/index .html.

Ontario Ministry of Agriculture Food and Rural Affairs. (2016, 8 January 2016). "Ontario Farm Data, Census of Agriculture, 1996, 2001, 2006, and 2011." 11 May 2012 (Kumuduni Kulasekara - Economist/OMAFRA). Retrieved 23 November, 2016, from http://www.omafra.gov.on.ca/english/stats/census/sum mary.htm.

Pearson, C. J., D. Bucknell and G. P. Laughlin (2008). "Modelling crop productivity and variability for policy and impacts of climate change in eastern Canada." Environmental Modelling \& Software 23(12): 1345 1355.

Poschlod, P. and R. Braun-Reichert (2016). "Small natural features with large ecological roles in ancient agricultural landscapes of Central Europe - history, value, status, and conservation." Biological Conservation.

Ramankutty, N., A. T. Evan, C. Monfreda and J. A. Foley (2008). "Farming the planet: 1. Geographical distribution of global agricultural lands in the year 2000." Global Biogeochemical Cycles 22(1).

Risser, P. G., J. R. Karr and R. T. T. Forman (1984). Landscape Ecology: Directions and Approaches, Illinois Natural History Survey: 22.

Schulte, L. A., M. Liebman, H. Asbjornsen and T. R. Crow (2006). "Agroecosystem restoration through strategic integration of perennials." Journal of Soil and Water Conservation 61(6): 165A-169A.

Statistics Canada. (2012, 25 January 2016). "Publication 95-640-X: Farm and farm operator data." Retrieved 23 November, 2016, from 
http://www.statcan.gc.ca/pub/95-640-

x/2011001/p1/prov/prov-35-eng.htm\#Farm_area.

Statistics Canada. (no date). "Census of Agriculture 2006 -

Data Accuracy." Retrieved 4 February, 2017, from

http://www23.statcan.gc.ca/imdb-

bmdi/document/3438_D2_T9_V1-eng.pdf.

Steiner, F. R. (1990). Soil Conservation in the United States: Policy and Planning. Baltimore, Maryland., Johns Hopkins University Press.

Sulc, R. M. and B. F. Tracy (2007). "Integrated croplivestock systems in the U.S. Corn Belt." Agronomy Journal 99(2): 335-346.

United States Department of Agriculture Farm Service Agency. (No date). "National Agriculture Imagery
Program." Retrieved 4 February, 2017, from https://www.fsa.usda.gov/programs-andservices/aerial-photography/imagery-programs/naipimagery/.

Watkins, M., S. Hilts and E. Brockie (2003). Protecting Southern Ontario's Farmland. Guelph, Ontario, Centre for Land \& Water Stewardship: 22.

Wright, C. K. and M. C. Wimberly (2013). "Recent land use change in the Western Corn Belt threatens grasslands and wetlands." Proceedings of the National Academy of Science USA 110(10): 4134-4139. 


\section{Table 1}

Conversion of AAFC annual crop layer cover types to study land cover types. Codes refer to pixel values in AAFC crop layer

\begin{tabular}{ll}
\hline Abbreviated Cover Type & AAFC Cover Type and Number \\
\hline Water & Water (20) \\
\hline Built & Exposed/barren (30); Developed/urban (34); Greenhouses \\
& $(35)$ \\
\hline Unknown agriculture & Agriculture, unknown (120) \\
\hline Annual crops & Too wet to be seeded (130); Fallow (131); Cereals (132); \\
& Barley (133); Other grains (134); Millet (135); Oats (136); \\
& Rye (137); Spelt (138); Triticale (139); Wheat (140); \\
& Winter wheat (145); Spring wheat (146); Corn (147); \\
& Tobacco (148); Ginseng (149); Oilseeds - other (150); \\
& Borage (151); Camelina (152); Canola (153); Flax (154); \\
& Mustard (155); Safflower (156); Sunflower (157); \\
& Soybeans (158); Pulses - other (160); Peas (162); Beans \\
& $(167) ;$ Lentils (174); Vegetables - other (175); Tomatoes \\
& $(176) ;$ Potatoes (177); Sugarbeets (178); Vegetables - \\
& other (179); Herbs (193); Buckwheat (195); Canary Seed \\
& $(196) ;$ Hemp (197); Vetch (198); Other crops (199) \\
\hline Short-term perennial cover & Pasture/forage (122); Switchgrass (141); Fruits - other \\
& $(180) ;$ Berries (181); Blueberry (182); Cranberry (183); \\
& Other berry (185); Orchard (188); Other fruits (189); \\
& Vineyards (190); Hops (191); Sod (192); Nursery (194) \\
\hline Long-term perennial cover & Shrubland (50); Wetland (80); Grassland (110); Forest - \\
& undifferentiated (200); Coniferous (210); Broadleaf (220); \\
& Mixed wood (230) \\
\hline & \\
\hline &
\end{tabular}

Table 2

Areas of annual, short-term perennial, and long-term perennial vegetation land cover types from 2011-2015 (ha)

\begin{tabular}{lrrrrrr}
\hline Vegetation Type & 2011 & 2012 & 2013 & 2014 & 2015 & Range \\
\hline Annual (crops) & 116,581 & 113,850 & 117,331 & 113,751 & 115,261 & 3,580 \\
Short-term perennial & 27,218 & 27,032 & 22,715 & 21,570 & 21,362 & 5,856 \\
Long-term perennial & 25,387 & 28,315 & 28,281 & 30,808 & 29,016 & 5,421 \\
\hline Sum & 169,186 & 169,197 & 168,327 & 166,129 & 165,639 & 3,558 \\
\hline
\end{tabular}

Table 3

Annual changes among three vegetated land cover types between 2011 and 2015 (expressed as percentage, rounded)

\begin{tabular}{lccccc}
\hline & $2011-12$ & $2012-13$ & $2013-14$ & $2014-15$ & $2011-15$ \\
\hline Annual cover & -2 & +3 & -3 & +1 & -1 \\
Short-term perennial cover & 0 & -2 & -5 & -1 & -22 \\
Long-term perennial cover & +11 & 0 & -8 & -5 & +14 \\
\hline
\end{tabular}




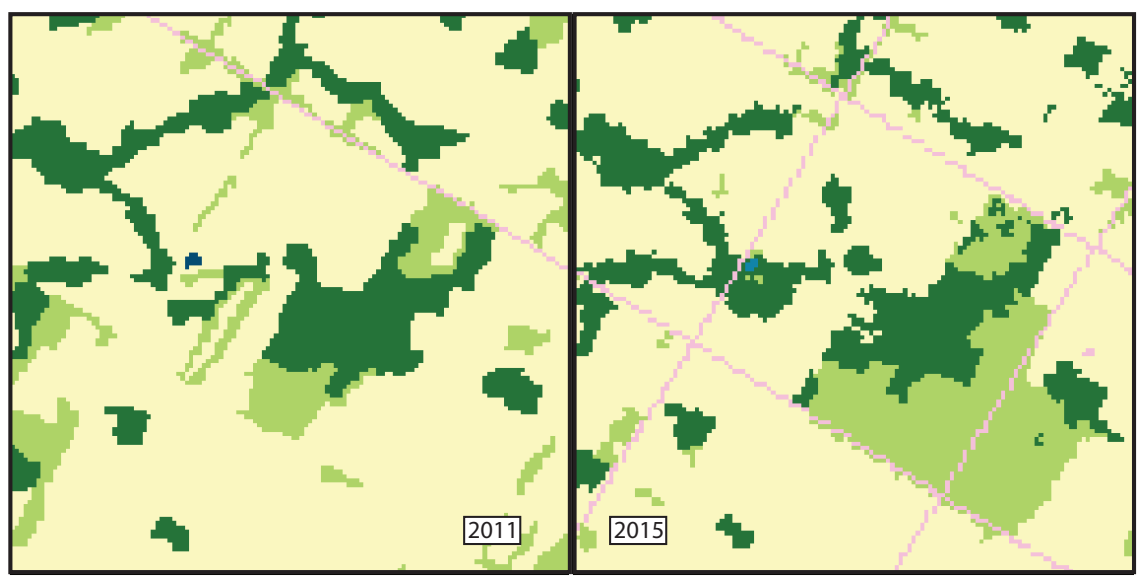

\section{Figure 1}

An example of the study area in 2011 and 2015 showing the representation of secondary roads (pink) amid annual crops (yellow), long-term perennial cover (dark green), and short-term perennial cover (light green) 


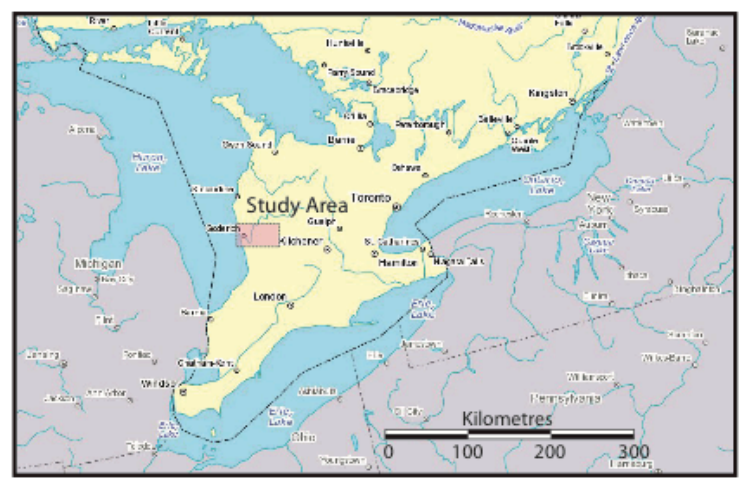

\section{Figure 2}

Context of study area in southern Ontario, Canada. Inset rectangle approximates study area boundary (SOURCE: Natural Resources Canada) 


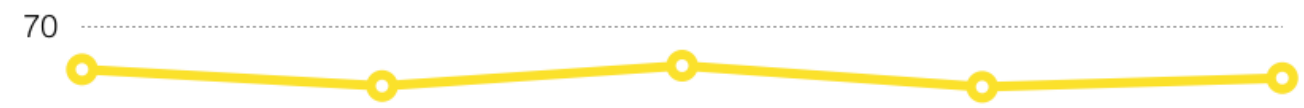

52.5

35

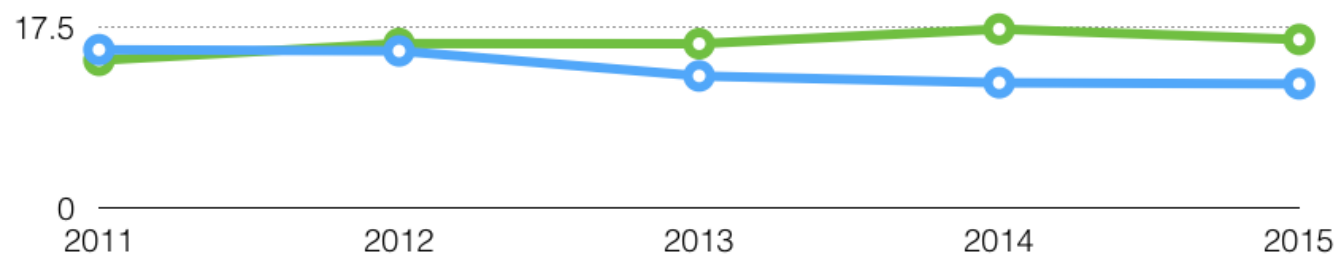

Figure 3

Proportions of annual (yellow line), short-term perennial (blue line), and long-term perennial (green line) vegetation types in the study area from 2011 to 2015 